\title{
EL EDIFICIO DE LA ADUANA DE MÉXICO. NOTAS PARA SU HISTORIA
}

\section{Por Ramón Gutiérrez}

El hallazgo de un interesante expediente que pude adquirir en una librerfa española me permitió reconstruir algunos datos de interés sobre la antigua Aduana de la ciudad de México que he tratado de ordenar para ofrecer al conocimiento de los investigadores mexicanos y americanos. 1

Del análisis de los antecedentes surge que el edificio que ocupara la Aduana de México con anterioridad al actual perteneció a Francisca María Bellvis Marquesa de Benavites y Villamayor por ser "poseedora del Mayorazgo que fundó Don Francisco de Pacheco y Vocanegra". 2

Este edificio ya en 1671 estaba deteriorado $y$, aunque a fines del Xvir se le hicieron reparaciones, sus paredes quedaron muy "sentidas" estimándose en 1723 que serían necesarios cerca de 40,000 pesos para concretar su reedificación. Ante la eventualidad la Marquesa gestiona autorización de venta y el Rey emite el 18 de diciembre de 1723 una Real Cédula inquiriendo a la Real Audiencia su parecer sobre el particular, notificando al hijo de la Marquesa don Joseph Vicente Bellvis y Moncada, Marqués de Belgida que reside en Valencia.

La Real Audiencia mexicana resuelve efectuar un peritaje sobre el estado de las edificaciones designando en febrero de 1726 a los Maestros "que lo son del arte de la arquitectura" Pedro de Arrieta y Antonio Álvarez, además de los licenciados Manuel Joseph Roldán de la Cueva y don Joseph Castilla abogados de la Audiencia. Pedro de Arrieta era en ese momento "Maestro Mayor del Reyno en el Arte de la Arquitectura y de la Fábrica Matherial de la Santa Iglesia Cathedral Metropolitana de esta ciudad y del Real Palacio de esta Corte", mientras que Antonio

1 Expediente "Número $6=$ Lio $=119$. Testimonio de las diligencias ejecutadas en virtud de Real Cédula de su Majestad para que se proceda a la venta de las Casas de la Aduana pertenecientes al Mayorazgo de la señora marquesa de Benavites y Villamayor." México. Diciembre 91 de 1729. 82 fojas.

Biblioteca Arquitecto Ramón Gutiérrez. Resistencia, Argentina. Se trata eviden. temente de una copia judicial y testimonios fechados en México a 6 de febrero de 1730 por Joaquín de Anzurez, Manuel de Esquibel y Tomás de Sigüenza.

2 Los datos mencionados entre comillas pertenecen al testimonio anterior salvo que expresamente se señale su fuente. 
Alvarez ejercía el cargo de Alarife Mayor de la ciudad de México, es decir ambos constituían los profesionales de mayor nota de la ciudad lo que habla a las claras de la importancia de la tarea encomendada.

Mientras la gestión de los abogados se refirió explícitamente sobre las utilidades económicas del inmueble, el peritaje de los Maestros se centró en el estado de obsolencia del mismo.

Así los primeros aconsejaron que se vendiese "siendo su producto para su reedificación pues de ejecutarlo resulta grande utilidad al Mayorazgo ... particularmente cuando su importe se ha de convertir e imponer por censo quedando para seguridad hipotecadas las mismas casas".

Por su parte los maestros reconocieron el edificio situado según declaran "en la Plazuela del Señor Santo Domingo, que hace esquina y da vuelta por la calle que llaman de la Perpetua y hoy sirve de Real Aduana". Su frente miraba al oeste con 47 varas de largo mientras que sobre la calle de la Perpetua totalizaba $481 / 3$ varas, a los que se sumaban otras $461 / 2$ varas "de un sitio erigido sin fábrica ninguna", totalizando así $945 ; 6$ varas, valuándose el terreno en 17,585 pesos.

La valuación del edificio comprendía "el material de las paredes maestras y tabiques, las medidas de los techos de vigas de oyamel de a 8 varas, las estapalucas y cantoneria de a 7 varas, las planchas de oyamel que reciben las maderas de los corredores, los pilares altos y bajos de piedra de cantería; los balcones y rejas voladas y lumbreras todos de fierro, los empedrados de zaguán y patio. Los envigados de los pasos de la escalera de piedra de Tenayuca. Los canales de piedra de cantería con los chiflones de plomo, pozo y pileta con sus brocales de mampostería" que totalizaban 9,705 pesos, dando de esta manera un valor total de 27,290 pesos.

Acotaban también los Maestros que era obra "tan antigua... pues es de lo primitivo que se fabricó en esta ciudad pues los primeros techos no llegan a 3 varas imposibilitados de habitarlos". Funcionaban allí además de la Real Aduana, algunas oficinas del Real Tribunal del Consulado, Contadurías y viviendas de los ministros de esta última repartición, la que tuvo a su cargo sucesivas reparaciones. El estado de la construcción era tan lamentable que los maestros consideraron "incapaz de reedificarse" aconsejando se fabricase de nuevo "haciendo por la parte de la plazuela tres casas en las $47 \frac{1}{2}$ varas, cada una de $152 / 3$ varas y los 48 de fondo que es el sitio que goza y en que está fabricada dicha Real Aduana y por la parte de la Calle de la Perpetua otras tres casas de a $151 / 3$ varas en el sitio eriazo referido" 
estimándose el costo de las seis casas en 54,000 pesos y que "según la necesidad de casas que hay en el paraje por estar en el comercio" podrían redituar tres mil pesos al año.

Aparentemente la inversión era cuantiosa y aunque la previsible recuperación de la misma era segura, la Marquesa de Benavides y Villamayor aduciendo no tener dinero para reedificar solicita autorización de venta en favor del Mayorazgo la que es otorgada por el Rey.

Fue así como en febrero de 1729 en "el Portalillo de este Rea] Palacio en que se celebran los Remates y Almonedas" el indio Juan Antonio Rodulfo que hacía el oficio de Pregonero sacó a remate las "casas altas principales que son en esta ciudad en la Plazuela que llaman de Santo Domingo y sirven de Real Aduana". Concluídos 30 pregones sólo fue realizada una postura por don Joseph Francisco de Landa en nombre del Convento de la Encarnación ofreciendo pagar los veintisiete mil doscientos noventa pesos de la tasación anterior.

Simultáneamente se comisiona a los maestros Pedro de Arrieta y Joseph Martínez de Herrera para que efectúen un nuevo reconocimiento y avalúo de "todas las salas principales, corredores y demás oficinas de la vivienda de los altos de toda la casa" y "asimismo los portales y oficinas donde está la Contaduría Principal de dicha Real Aduana" y los cuartos debajo de los portales, canales y sitio eriazo. Señalan los maestros que "las viviendas de dichas casas se componen por lo bajo de zaguán, patio, el cuarto del portero que se compone de tres piezas, otro cuarto de otro portero con dos piezas y una cocina, tres bodegas, cuatro piezas de contadurías, una vivienda que se compone de cinco piezas con la cocina, una azotegüela, corral, escalera que da a patio a ellas, dos caballerizas, otra vivienda que se compone de patio, otro cuarto por lo bajo, corral, escalera que da paso a la vivienda alta". Esta vivienda alta se componía de tres piezas, cocina, azotegüela y corral de gallinas, mientras que la vivienda de la esquina sobre la plazuela tenía sala, escritorio, cuarto de mozo, dormitorio, cuarto comedor y despensa "dando vuelta por el lado del sur con un cuarto pequeño fabricado sobre el corredor, cocina, otro cuarto que se le sigue, otros dos cuartos de mozos con corral de gallinas y gallineros, todos los cuales dichas piezas las habitan los Ministros de dicha Real Aduana".

Los pilares de la casa eran de piedra de cantería o de chiluca, la escalera principal de piedra de Tenayuca y las paredes de "mezclas de cal y tierra" y "tapiales de quartones". 
La valuación de la Real Aduana fue similar a la de tres años antes, pero es interesante señalar que ésta más minuciosa descripción evidencia el neto corte residencial que predomina en el uso funcional del edificio, donde podemos detectar la existencia de cinco viviendas de diferentes tamaños.

El 18 de mayo de 1729 se venden las casas a las Religiosas de la Encarnación quienes al tomar posesión de las mismas se habian comprometido a entregar al Real Tribunal del Consulado "diez varas de frente que caen a la Plazuela de Santo Domingo y la parte de dicho Convento, de las 13 varas de fondo de las casas que fueron de el referido Mayorazgo de don Francisco de Oñate y Azoca y en que hoy se está labrando la Real Aduana y caen a la calle de la Iglesia de dicho Convento de Santo Domingo".

Estas informaciones permiten precisar diversos elementos de juicio. En primer lugar la vieja aduana era adyacente al nuevo edificio realizado en el solar de Oñate y no en el de Villamayor como cree el arquitecto Federico Mariscal. ${ }^{3}$ La organización del conjunto se realizó a partir de la construcción del convento de Santo Domingo comenzando en 1526 y concluído en 1575.4

No es exacto aparentemente que "la Aduana fue pasada a este lugar en 1686" pues del texto se deduciría que ya en 1671 tenía carácter de tal el edificio, que según Flores Marini fue muy afectado por las inundaciones de 1629 que determinó el abandono del setenta y cinco por ciento de las casas de México. ${ }^{5}$

La nueva iglesia de Santo Domingo fue realizada hacia la misma época en que Pedro de Arrieta levantó el nuevo edificio de la Aduana, obra ésta concluida en junio de 1731, mientras que Santo Domingo se consagró en 1736 teniendo originariamente un atrio cercado que fuera demolido en 1861 .

El nuevo edificio de la Aduana significó la adopción de una tipología donde aparecen los enormes portones que comprenden "la altura de

3 Mariscal, Federico E. La Patria y la Arquitectura Nacional. Impresora del Puente Quebracho. Segunda Edición. México, 1970.

4 México en el tiempo, fisonomia de una ciudad. México, 1945. Allf se señala que la casa del conquistador Diego de Oñate, fue destinada a nueva Aduana.

5 Flores Marini, Carlos. Casas virreinales en la ciudad de México. Fondo de Cultura Económica. México, 1970. 
DOI: http://dx.doi.org/10.22201/iie.18703062e.1975.44.2347

Comero $6 I_{10}=119$

TEST de las diluxen." Executadas In vixtud de Ri Cedula Doe S. Mas. para que se proceda ala Zen ta. de las Casas de la Clduana, per tenecientes al Cliayorasog de la Siñox.a CAarquesa de Benavites y Vitua mayor.

Mrgice

Did 3

d61729

13. H 


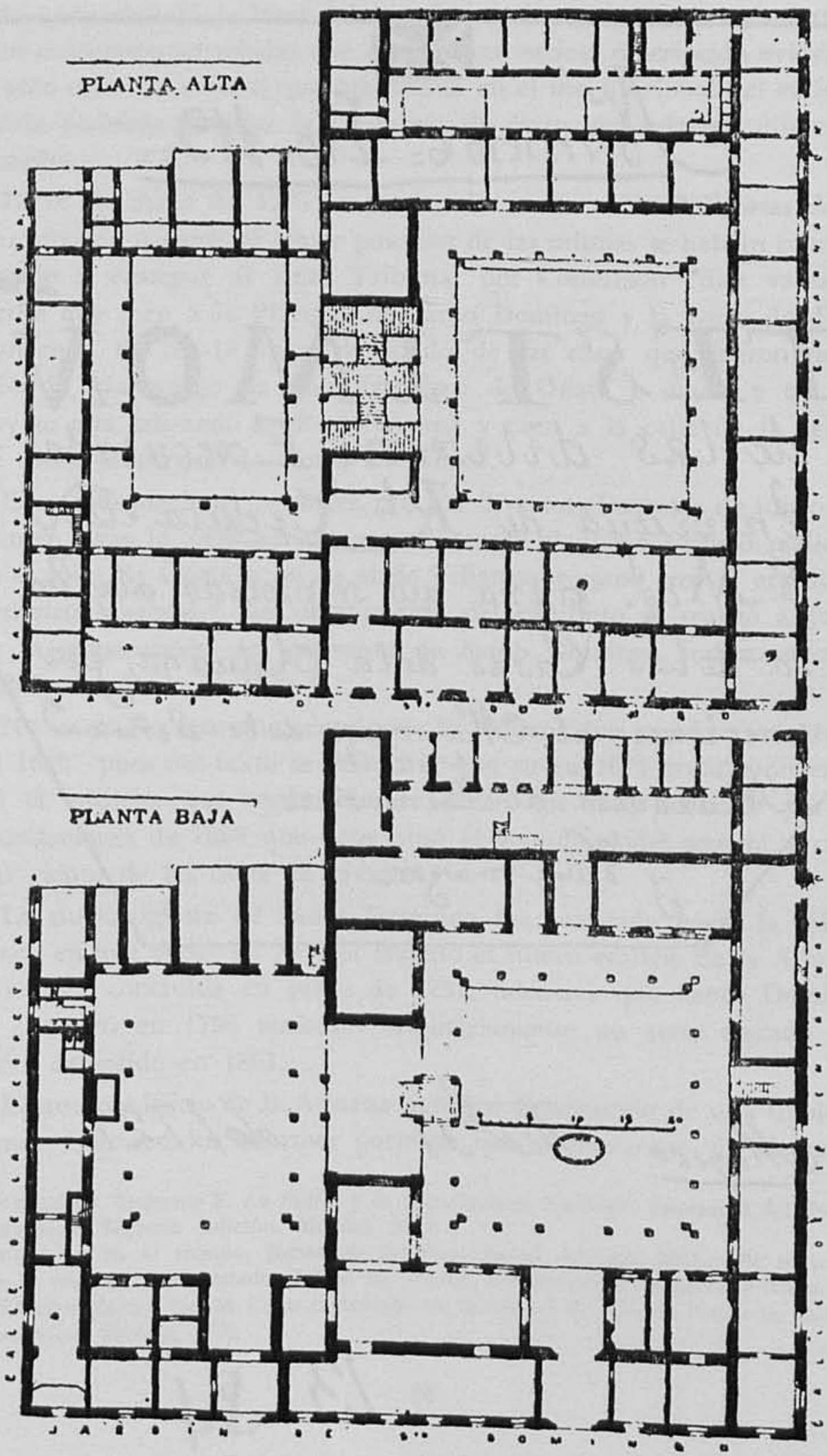

2. México, D. F. Ex aduana de Santo Domingo. Plantas. 
DOI: http://dx.doi.org/10.22201/iie.18703062e.1975.44.2347

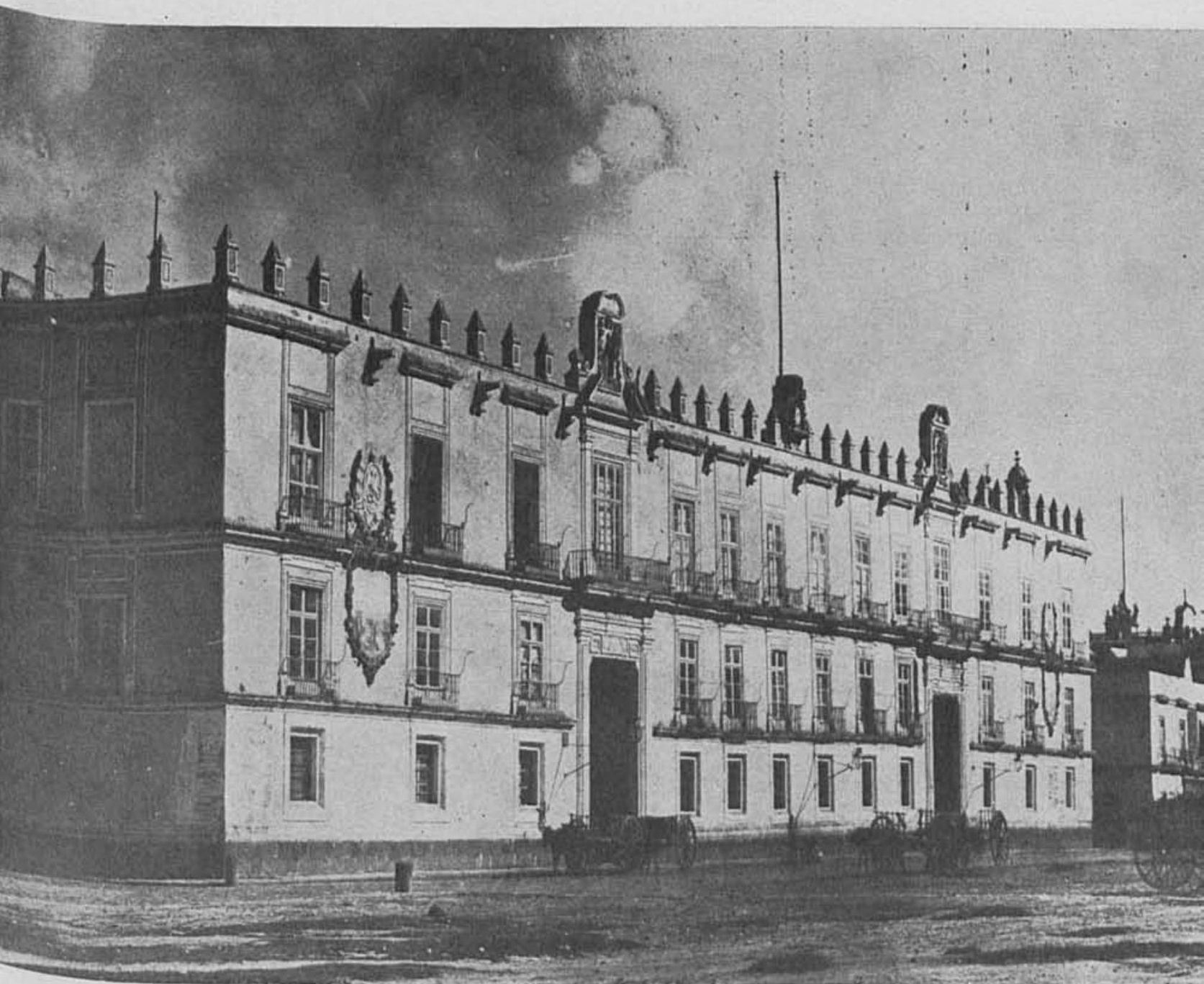

3. México, D. F. Ex aduana de Santo Domingo. Hacia 1880. Foto Archivo del I. N. A. H. 
DOI: http://dx.doi.org/10.22201/iie.18703062e.1975.44.2347

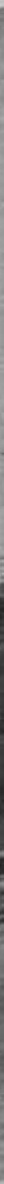

4. México, D. F. Ex aduana de Santo Domingo. Hacia 1930. Foto Archivo del I. N. A. H. 
DOI: http://dx.doi.org/10.22201/iie.18703062e.1975.44.2347

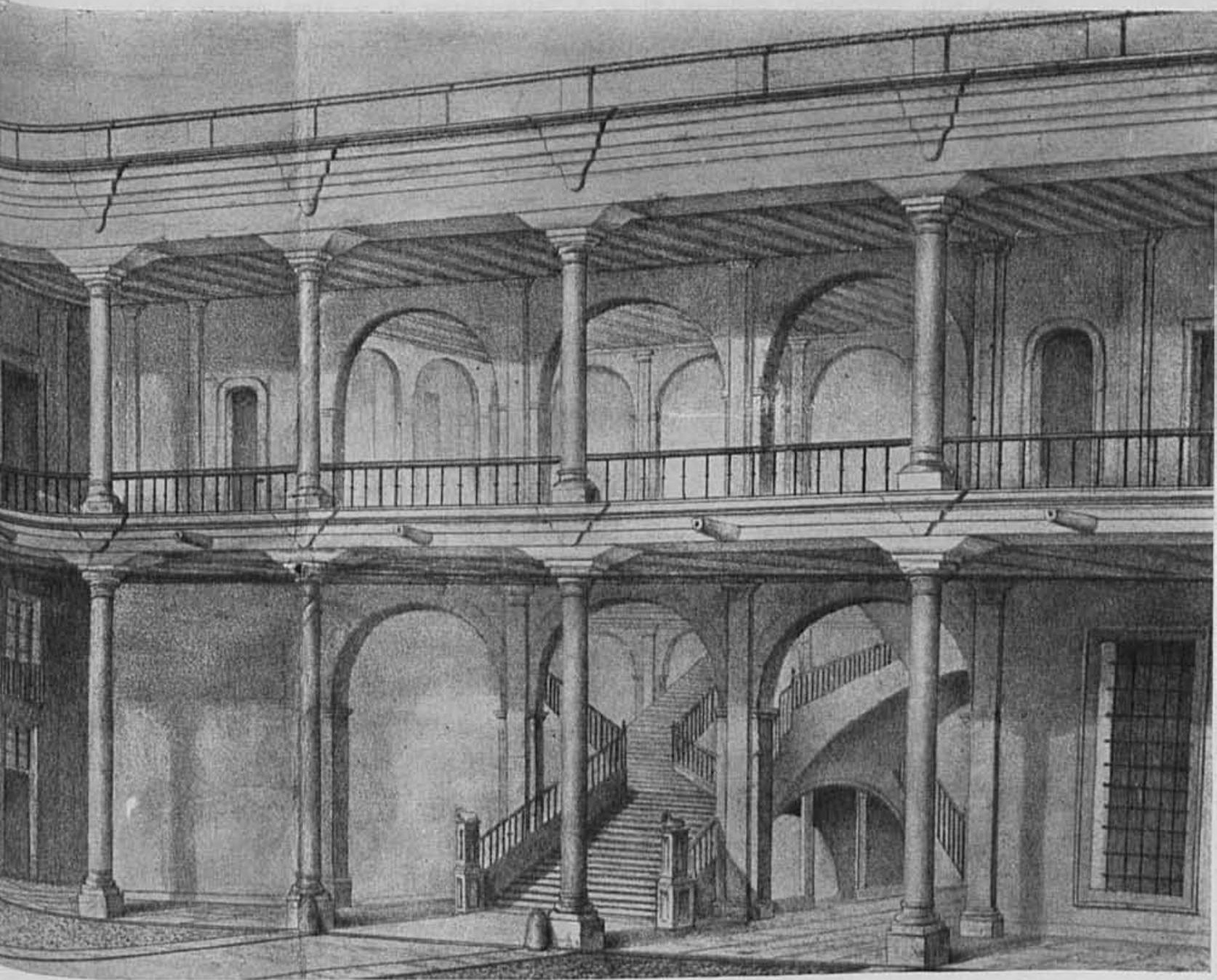

5. México, D. F. Ex aduana de Santo Domingo. Patio principal. Litografia siglo xIx. Foto Archivo del I. N. A. H. 
DOI: http://dx.doi.org/10.22201/iie.18703062e.1975.44.2347 
la planta baja y el entresuelo", ${ }^{\circ}$ y la escalera principal que actúa de pivote para los dos patios sucesivos. ${ }^{7}$

Cierto desajuste evidente entre los dos patios y en el partido arquitectónico de la Nueva Aduana (según el plano que reproducimos) nos hacen pensar que se trata de dos edificios unidos o por lo menos no concebidos en su totalidad desde un comienzo.

El cuerpo más pequeño, ubicado sobre la calle de la Perpetua se evidencía como autónomo y el tamaño de sus habitaciones es ligeramente inferior al nuevo diseño de Pedro de Arrieta.

No sabemos si en definitiva se trata de una reedificación realizada en el antiguo solar de la marquesa de Villamayor por los nuevos propietarios, aunque, descartada evidentemente la realización de casas de renta, nos inclinamos a pensar que fuera adquirido finalmente por la Aduana para la ampliación de su sede.

Las diez varas cedidas al Consulado, podrían así explicar el martillo existente, como penetración de una obra en la otra, en la planta baja o el volumen de transición que ocupa la magnífica escalera de Arrieta.

La participación del mismo alarife en la tasación de la antigua aduana y en la construcción de la nueva podrian haber favorecido las posibilidades de una adquisición y agregación. Algo que al no surgir de la documentación que poseemos sólo podemos adelantar como hipótesis.

- Rojas, Pedro. Historia General del Arte Mexicano. Época Colonial. Editorial Hermes, S. A. México, 1963.

7 Toussaint, Manuel. Arte Colonial en México. Instituto de Investigaciones Estéticas. UNAM. México, 1948. 